Composites

Research
Vol.26, No. 2, 135-140 (2013)

DOI: http://dx.doi.org/10.7234/composres.2013.26.2.135

ISSN 2288-2103(Print), ISSN 2288-2111(Online)

$\underline{\text { Paper }}$

UHPC 바닥판 증기양생 현장이음부의 최소철근겹침이음길이

황훈희*广 . 박성용**

\title{
The Minimum Lap-spliced Length of the Reinforcement in the Steam Curing UHPC Bridge Deck Slab Joint
}

\author{
Hoon-Hee Hwang**, Sung-Yong Park**
}

\begin{abstract}
The static test was performed to verify the effect of the joint in the UHPC bridge deck slab and the minimum lap-spliced length was presented. A total of six test members was fabricated to estimate the static behavior of the steam curing UHPC bridge deck slab joint by the four points bending test method. The lap-spliced joint type was expected to be not only simple but also efficient in UHPC structure because of the high bond stress of UHPC. Test results show that the decrease of maximum flexural strength was about $30 \%$ and the minimum lap-spliced length which behaved similar to the continued reinforcement in strength and ductility was $150 \mathrm{~mm}$.
\end{abstract}

\begin{abstract}
초록: 이 연구에서는 이음부가 초고성능콘크리트 교량 바닥판의 정적 거동에 미치는 영향을 실험적으로 규명하 고, 이음부 철근의 최소겹침이음길이를 제안하였다. 총 6개의 실험부재를 제작하였으며 4점 휨 실험에 의하여 성능 을 평가하였다. 이음부는 UHPC의 높은 부착특성으로 인하여 단순하면서도 매우 효율적인 구조가 될 것으로 기대 되는 철근겹침이음을 대상으로 하였다. 실험결과로부터 이음부의 설치에 의한 UHPC의 인장기여도 감소에 따라 약 $30 \%$ 수준의 휨강도 감소가 발생되는 것으로 측정되었고, $150 \mathrm{~mm}$ 이상의 철근겹침이음길이를 확보하면 연속된 철 근을 사용한 경우와 거의 유사한 강도와 연성을 확보할 수 있는 것으로 나타났다.
\end{abstract}

Key Words: 초고성능콘크리트(UHPC), 철근겹침이음(lap-spliced joint), 이음부(joint), 4점 휨시험(4 points bending test)

\section{1. 서 론}

초고성능콘크리트(Ultra High Performance Concrete, 이하 $\mathrm{UHPC})$ 는 향후 건설 시장에서의 활용가치가 높을 것으로 기대되는 재료 중 하나이다. 이러한 기대는 단지 높은 강도 와 내구성 등 건설재료로서 UHPC가 가지는 수치적 성능 에 기인한 추상적 단계를 넘어 일반적인 콘크리트 구조물 의 한계를 극복하고 혁신적인 설계와 시공을 가능하게 할 수 있는 연구와 실적이 증가함에 따라 점차 현실화되어 가 는 추세이다[1-3].
최근에는 급속시공을 위한 기술적 추세를 반영하여 프 리캐스트 공법을 적용한 사례가 증가하고 있으며 이에 따 라 이음부에 대한 연구도 수행되고 있다. Perry와 Seibert[4] 는 기존의 철근콘크리트구조에 UHPC를 채움제로 활용하 는 프리캐스트 이음부에 대한 연구와 사례를 고찰하였고, Martin과 Werner[5]는 목재와 UHPC의 부착특성을 연구하 였으며 Raafat과 Donna[6]는 압축측 단면을 UHPC로 채운 중공 유리섬유복합소재(Glass fiber reinforced plastic) 합성 보의 경계면 거동을 연구하는 등 서로 다른 재료간의 부착 특성에 근거한 다수의 사례가 보고되었다. 그러나 UHPC 
를 주재료로 하는 구조시스템 특히 프리캐스트 바닥판의 이음부에 대해서는 소수의 사례가 보고되었다. Graybeal 등 [7]은 단면상세를 변수로 하는 프리캐스트 바닥판 이음부 의 성능평가를 위한 실험을 수행하였고, 국내에서는 강재 거더와 UHPC 바닥판의 스터드를 이용한 합성거동 평가와 단면 중앙위치에 보강철근이 배근된 UHPC 프리캐스트 휨 부재의 철근겹침이음 성능 평가 등의 사례를 살펴 볼 수 있 다[8,9]. 이러한 선행 연구 사례들로부터 UHPC의 높은 강 도 및 부착 특성을 이용하여 이음부 크기의 축소와 상세의 단순화가 가능함이 공통적으로 입증되었으나 아직까지는 연구의 초기단계로서 연결부 형태와 단면상세에 따라 보 다 많은 실험적 검증이 수행되어야 한다.

이 연구에서는 교량의 바닥판과 같이 얇은 부재에 적합 한 가장 단순한 연결형태인 철근겹침이음부 설치에 따른 $\mathrm{UHPC}$ 휨부재의 정적인 거동변화를 실험적으로 규명하고 최소철근겹침이음길이를 산정하였다. 대상 부재는 UHPC 바닥판 프리캐스트 세그먼트를 모사한 휨부재이며, 선행연 구와 비교할 때 철근을 인장측으로 배근하여 단면효율성 을 개선한 모델이다.

\section{2. 실 험}

\section{1 실험부재 구성}

모든 실험부재는 동일한 외형적 제원과 단면상세로 제 작되었으며 연구의 목적에 따라 이음부를 갖지 않는 경우 와 연속된 철근을 사용한 경우를 포함하여 철근겹침이음 길이에 따라 총 6 개로 구성하였다.

실험부재의 제원은 길이 $2 \mathrm{~m}$, 폭 $0.5 \mathrm{~m}$, 두께 $150 \mathrm{~mm}$ 이며, 중앙의 현장이음부는 길이가 $250 \mathrm{~mm}$ 로서 프리캐스트부 UHPC의 양생을 끝낸 뒤 이음부 UHPC를 타설하는 분할타 설에 의하여 구현하였다. 단, 일정한 품질관리 수준이 유지 됨을 가정하여 증기양생을 실시하였다.

실험부재의 구성과 상세를 Table 1에 정리하였다. 여기서 $\mathrm{NC}$ 는 이음부를 갖지 않는 실험부재를 이르며, C-는 이음 부를 갖는 경우로서 아라비아 숫자는 철근의 겹침이음길 이를 표시한다. 따라서 C-0는 이음부는 있으나 철근은 이

Table 1. Specification of test members

\begin{tabular}{|c|c|c|c|c|}
\hline \multirow{2}{*}{ Specimens } & \multicolumn{3}{|c|}{ Dimension $(\mathrm{mm})$} & \multirow{2}{*}{$\begin{array}{l}\text { Lap-spliced } \\
\text { length }(\mathrm{mm})\end{array}$} \\
\hline & Length & Width & Height & \\
\hline NC & \multirow{6}{*}{2000} & \multirow{6}{*}{500} & \multirow{6}{*}{150} & - \\
\hline $\mathrm{C}-0$ & & & & - \\
\hline C-50 & & & & 50 \\
\hline C-100 & & & & 100 \\
\hline $\mathrm{C}-150$ & & & & 150 \\
\hline C-200 & & & & 200 \\
\hline
\end{tabular}

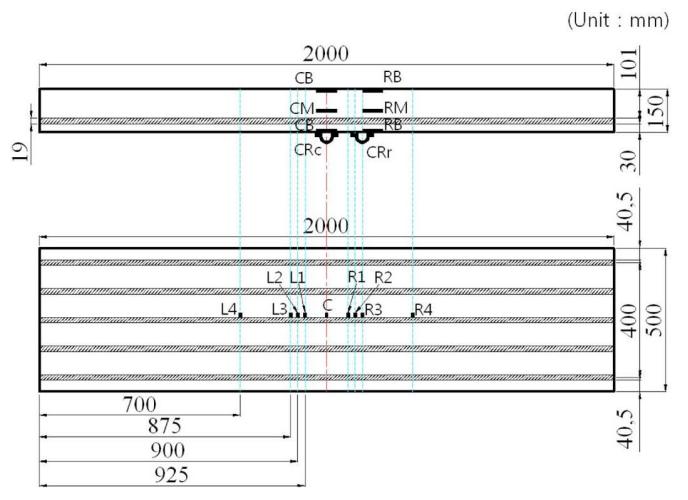

(a) NC

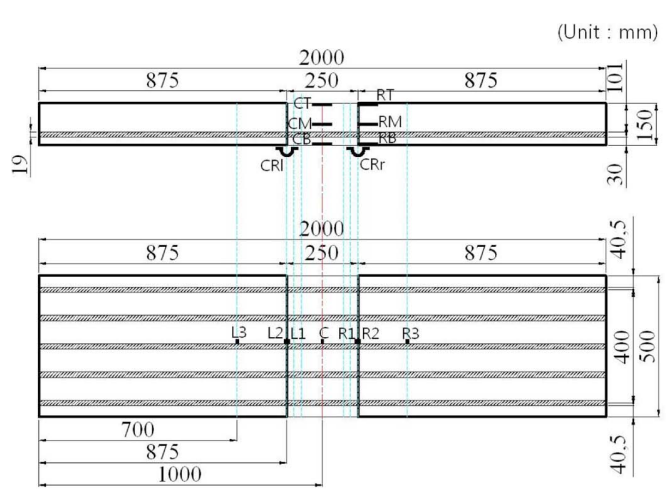

(b) $\mathrm{C}-\mathrm{O}$

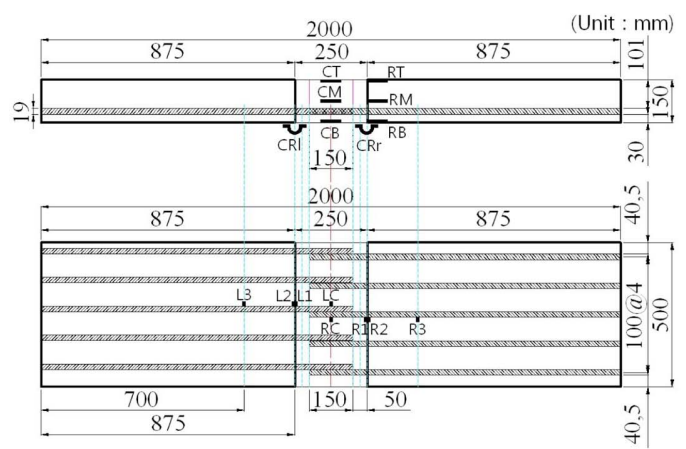

(c) C-150

Fig. 1. Dimensions and Details of the test members.

음없이 연속되게 배근한 실험부재이다. 각 부재의 형상과 특징적인 제원은 Fig. 1에서 살펴볼 수 있다.

한편, 재료실험으로부터 구한 UHPC의 압축강도와 인장 강도는 프리캐스트 부재가 각각 $178 \mathrm{MPa}$ 과 $11.1 \mathrm{MPa}$ 이고, 이 음부가 각각 $186 \mathrm{MPa}$ 과 $11.3 \mathrm{MPa}$ 이다. 철근은 항복강도 $400 \mathrm{MPa}$ 급의 직경 $19.1 \mathrm{~mm}$ 등급의 한국산업표준(Korea Standard) 인증제품을 사용하였다.

\section{2 정적재하실험}

이음부 설치에 따른 실험부재의 정적거동을 규명하기 위 


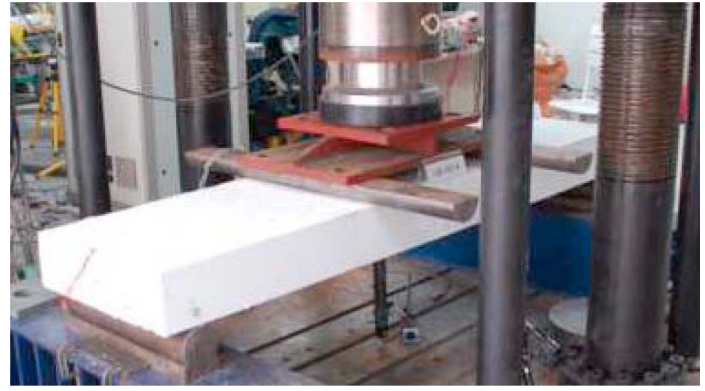

Fig. 2. 4-points bending test.

해 이음부 구간에 최대휨모멘트를 유발할 수 있도록 4점 재 하 방식의 휨실험을 실시하였다.

지지점은 파괴시의 안전을 고려하여 실험부재의 양측 끝 단으로부터 안쪽으로 $100 \mathrm{~mm}$ 씩의 여유를 확보하였으므로 지지점 사이의 간격은 $1.8 \mathrm{~m}$ 이며, 재하 위치는 전단거동의 간섭을 배제하기 위하여 이음부가 최대모멘트 구간에 충 분히 포함되도록 이 간격을 3 등분하는 것으로 계획하였 다. 따라서 지지점 및 하중 사이의 각각의 간격은 $600 \mathrm{~mm}$ 이며, 최대모멘트는 중앙부 $600 \mathrm{~mm}$ 구간에 발생되므로 $250 \mathrm{~mm}$ 의 폭을 가지는 이음부는 최대모멘트 구간에 충분 히 포함되는 것으로 판단된다.

하중은 한 개의 유압식 가력기와 프레임을 통하여 $600 \mathrm{~mm}$ 의 간격을 가지도록 계획된 두 재하위치에 동시에 작용하 며 변위제어방법(Displacement control method)에 의하여 $0.02 \mathrm{~mm} / \mathrm{sec}$ 속도로 재하되도록 하였다. 이 때 정적거동 분 석을 위하여 Fig. 1에 표시한 바와 같이 실험부재 중앙에서 의 처짐, 중앙단면과 이음부 경계면의 콘크리트 변형률, 철 근변형률 등을 측정하였다. 실험 전경은 Fig. 2에 나타내었다.

\section{3. 결과분석}

\section{1 하중-변위 관계}

정적재하실험에서 측정된 하중과 변위의 관계를 살펴보 았다. 하중 재하 초기부터 실험 종료시까지 측정된 하중변위 관계 곡선을 실험부재별로 Fig. 3에 나타내었으며, 실 험부재별 최대하중값과 이 때의 변위값을 Table 2에 정리 하였다.

먼저 이음부의 설치에 따라 예상할 수 있는 바와 같이 이 음부를 갖는 C-실험부재는 이음부를 갖지 않는 $\mathrm{NC}$ 실험부 재에 비하여 하중-처짐 곡선의 초기 기울기가 다소 낮게 형 성되었고, 최대하중값은 약 $70 \%$ 수준으로 나타났다. UHPC 의 높은 부착성능에도 불구하고 모재가 동일한 UHPC로 제 작되었고 강재거푸집으로 마무리된 매끈한 면에 이음부 UHPC 가 타설되었으므로 이음부 경계면을 따라 재하 초기부터 진전된 균열이 기울기 감소의 원인으로 판단되며, 경계면 에서 $\mathrm{UHPC}$ 의 단절에 따른 강섬유의 인장기여도 감소가 최

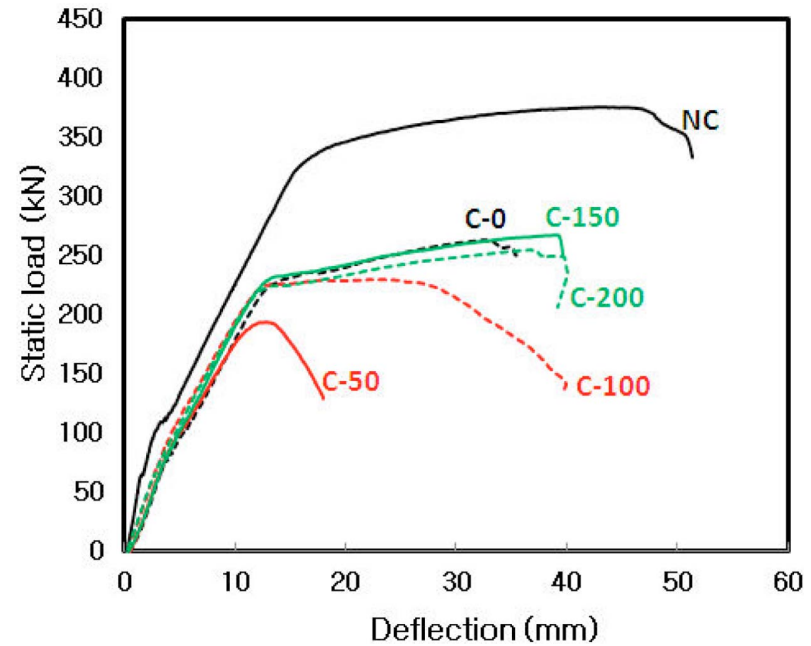

Fig. 3. Load-deflection relationship curves.

Table 2. Results of maximum loads and deflections

\begin{tabular}{c|c|c}
\hline Specimens & Maximum load $(\mathrm{kN})$ & Deflection $(\mathrm{mm})$ \\
\hline NC & 376.4 & 43.0 \\
\hline C-0 & 263.1 & 32.6 \\
\hline C-50 & 194.1 & 12.8 \\
\hline C-100 & 230.4 & 22.9 \\
\hline C-150 & 267.5 & 39.1 \\
\hline C-200 & 255.2 & 36.8 \\
\hline
\end{tabular}

대하중이 낮게 나타나는 이유로 볼 수 있다. 한편, Table 2 에 정리된 변위는 최대하중에 대응되는 값으로서 변형연 화(Softening) 거동을 고려한 실험부재의 최대변위는 아니다.

이음부를 갖는 실험부재들에서는 철근의 겹침이음길이 에 따라 구분되는 거동의 차이를 살펴볼 수 있다. C-150과 C-200 부재는 C-0와 거의 유사한 거동을 보여 겹침이음부 의 미끄러짐(Slip) 등은 매우 미소하여 휨거동에 영향을 미 치지 않는 수준으로 판단된다. C-100 부재는 항복점까지는 유사하게 거동하였으나 그 이후 경화(Hardening)없는 소성 거동이 관찰되며 최대하중이 $12 \%$ 정도 감소되는 차이점을 보였다. C-50 부재는 철근이 항복점에 도달하기 이전에 부 재의 파괴가 관찰되었다.

\section{2 파괴형상}

하중-변위 관계에서 철근겹침이음길이에 따라 나타난 거 동의 차이는 파괴형상에 대한 관찰을 통해서도 설명될 수 있다.

파괴형상은 크게 두 가지로 나타났다. 먼저 Fig. 4에서 볼 수 있는 바와 같이 프리캐스트부와 이음부의 양측 경계면 을 따라 진전되는 균열에 의한 파괴로서 균열은 초기부터 취약부인 부착면을 따라 진전된다. 이 경우는 연속된 철근 을 배근하여 경계면에서의 파괴를 의도적으로 유도한 실 


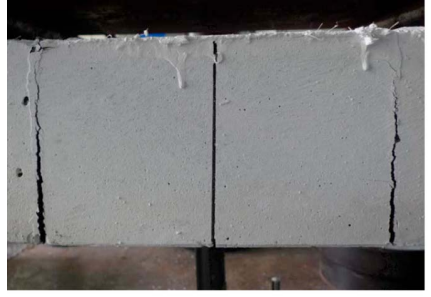

(a) side surface

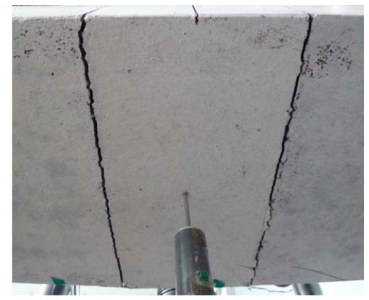

(b) bottom surface
Fig. 4. Crack propagation at the precast member-joint interfaces (C-150).

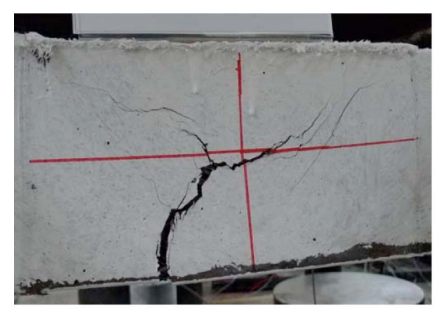

(a) side surface

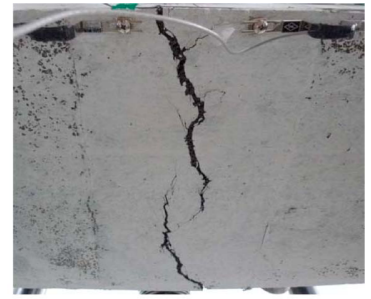

(b) bottom surface
Fig. 5. Crack propagation at the center section of the joint (C-50).

험부재인 C-0에서 관찰되었으며, C-150 및 C-200 부재에서 동일한 파괴형상이 관찰되었다. 따라서 두 실험부재는 철 근이 항복 이후의 거동을 할 때까지 이음부 내부의 철근겹 침이음에서 미끄럼(Slip)이 발생되지 않는 것을 예상할 수 있으며, 충분한 철근겹침이음길이를 확보하였으므로 Fig. 3 의 하중-변형 관계에서 연속된 철근을 갖는 C- 0 와 거의 동 일한 거동을 보인 것으로 판단된다.

다른 파괴형상은 이음부 중앙 하단에서 상단측으로 진 전되는 균열에 의한 파괴이며 Fig. 5에 나타내었다. 이 경우 는 이음부가 없는 NC 실험부재와 이음부를 가지며 상대적 으로 철근겹침이음길이가 짧은 C-50 및 C-100 실험부재에 서 관찰되었다. 이음부가 없는 경우는 최대모멘트가 작용 되는 중앙단면 하단에서 초기 균열이 진전되며 이 과정에 서 UHPC의 인장기여에 따라 강섬유가 철근과 함께 인장 에 저항하므로 Fig. 3에서 NC 실험부재의 강성 및 최대하 중이 상대적으로 크게 나타났다. 그러나, C-50 및 C-100 실 험부재는 초기 균열이 이음부의 양측 프리캐스트 부재와 의 경계면을 따라 진전되므로 초기에는 이음부를 가지는 다른 실험부재의 거동과 유사하지만 철근의 항복 이전 또 는 비슷한 하중단계에서 철근겹침이음길이의 부족으로 인 한 미끄러짐(Slip)이 발생되어 파괴에 도달하므로 최대하 중이 상대적으로 저하되며, 이음부 중앙에서 진전되는 균 열에 의하여 파괴에 도달하였다.

\section{3 하중-변형률 관계}

하중재하에 따른 변형률 관계는 이음부의 유무에 따라

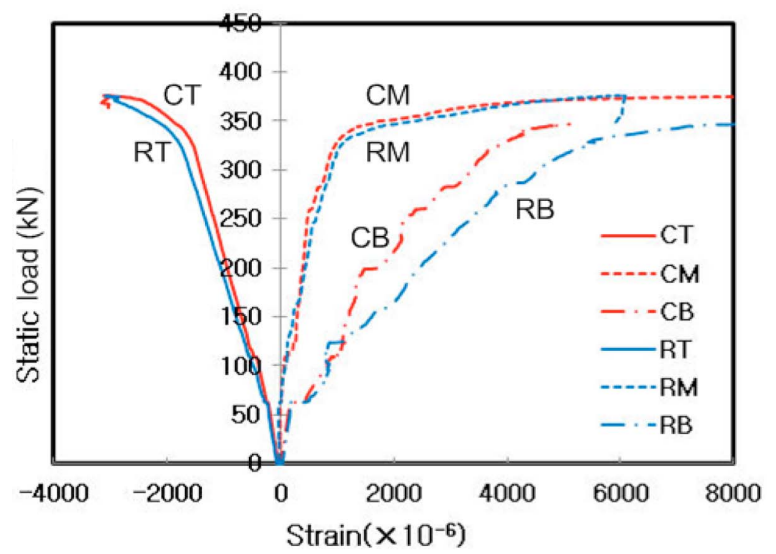

(a) NC

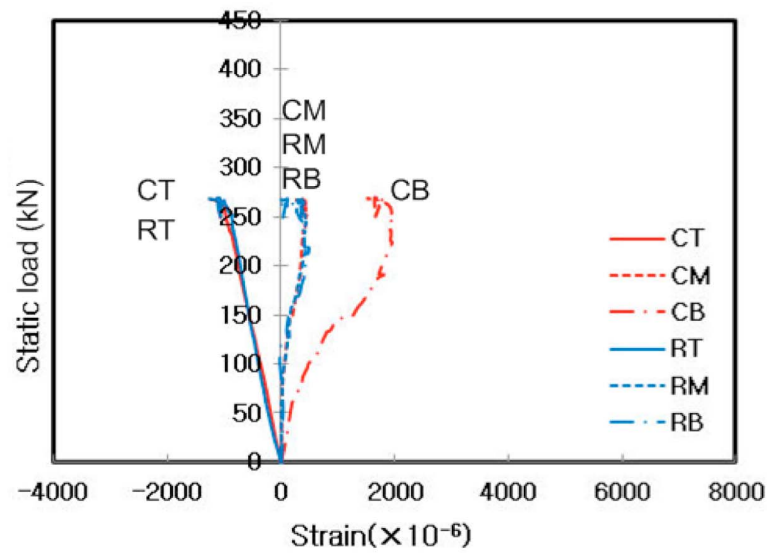

(b) $\mathrm{C}-\mathrm{O}$

Fig. 6. Load-UHPC strain relationship curves.

크게 구분되었으므로 대표적으로 NC 및 C-0 실험부재에 대하여 고찰하였다. 변형률의 측정은 실험부재 측면 UHPC 표면과 인장철근에서 실시하였으며 상세한 위치는 Fig. 1(a) 및 Fig. 1(b)에서 찾아볼 수 있다.

UHPC 표면에서 측정된 변형률 거동의 차이는 Fig. 6에 나 타내었다. 범례에서 변형률 게이지 명칭 중 앞글자는 실험 부재 중심부인 중앙단면을 $\mathrm{C}$, 이음부 경계면의 우측인 우 측단면을 $\mathrm{R}$ 로 표현하였고, 뒷글자는 단면에서의 높이로서 상단 $\mathrm{T}$, 중간 $\mathrm{M}$, 하단을 $\mathrm{B}$ 로 표시하였다. 이음부가 없는 $\mathrm{NC}$ 실험부재는 Fig. 6(a)에서 보는 바와 같이 균열 발생 이전까 지 상단은 압축, 하단은 인장 변형률이 대칭적으로 측정되 며, 중간 위치에서는 변형이 생기지 않았다. 균열 발생으로 예상되는 약 $70 \mathrm{kN}$ 의 하중부터는 하단의 인장측 변형률이 급격히 증가되었으며 중간위치에서도 인장변형률이 증가 되어 하중이 커짐에 따라 중립축의 상승과 균열의 진전을 예측할 수 있다. 이는 일반적인 철근콘크리트 휨부재와 유 사하며, 중앙단면과 우측단면에서 거의 동일한 결과가 측 정되었다.

그러나, C-0 실험부재에서는 Fig. 6(b)와 같이 이음부로 인 


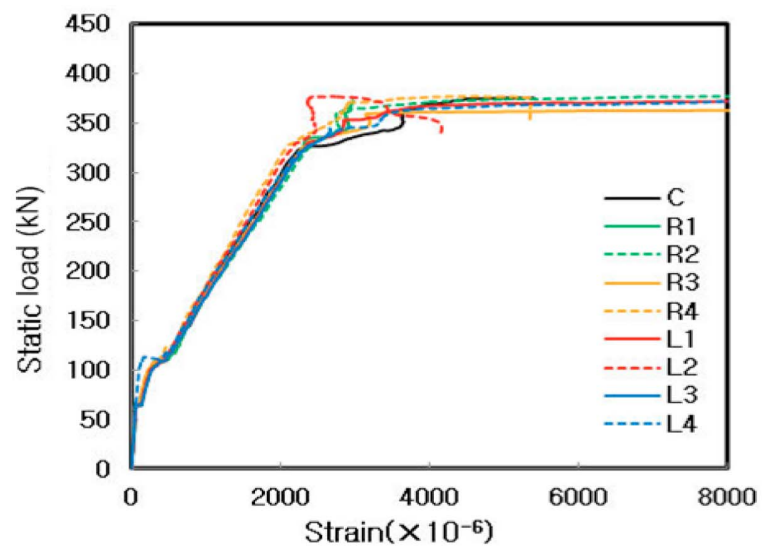

(a) NC

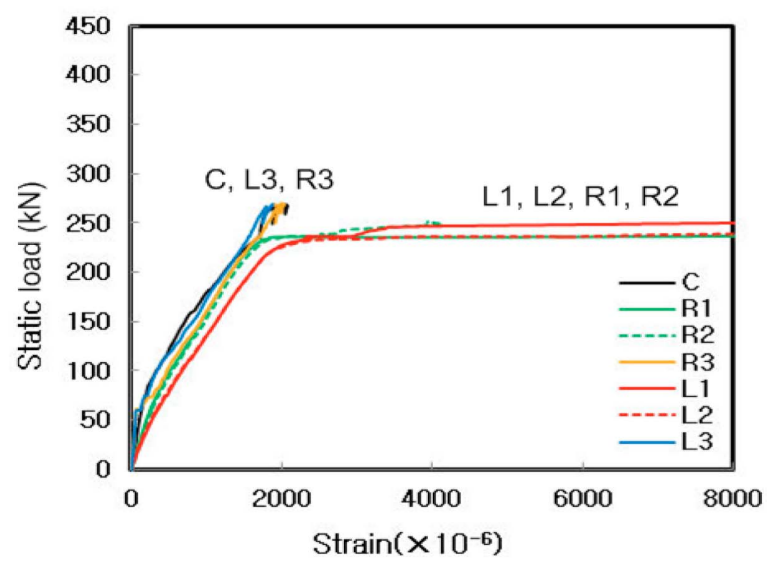

(b) $\mathrm{C}-\mathrm{O}$

Fig. 7. Load-rebar strain relationship curves.

하여 다른 거동이 관찰되었다. 이음부 경계면의 이격에 따 라 균열이 진전되므로 초기 균열발생 시점이 명확하지 않 으며, 중앙단면에서와는 달리 우측단면에서 하단 RB의 변 형률값이 중간위치인 RM과 거의 유사하게 나타나고 있다. 이는 이음부 경계면에서 UHPC의 인장저항 기여가 미미하 기 때문이며 이음부 경계면 위치의 철근에 인장력이 집중 될 것으로 예상된다.

철근의 변형률을 나타낸 Fig. 7에서도 이음부의 영향을 살펴볼 수 있다. NC 실험부재에서는 최대모멘트 구간에 설 치된 모든 게이지에서 소성거동이 기록되었으나, C-0 실험 부재는 이음부 경계면 위치(L1, L2, R1, R2)에서 소성거동 이 관찰되었고 중앙(c)과 프리캐스트 부재 내부 위치(L3, R3) 는 상대적으로 작은 값을 나타내었다. 즉, 이음부가 있는 경 우에는 경계면에서 측정된 철근의 변형률이 상대적으로 크 게 나타났으며 이음부 중앙 또는 프리캐스트 부재에서와 는 달리 소성거동을 보임으로써 휨에 의한 인장력이 이음 부 경계면 철근에 집중되고 있음을 알 수 있다. 연속된 실 험부재는 변형률 게이지의 위치에 관계없이 모두 소성거 동을 나타내어 휨에 의한 인장에 대해 고르게 저항하였다.

\section{4. 결 론}

얇은 부재에 적합하고 UHPC의 높은 부착특성을 활용할 수 있는 가장 단순하고 효율적인 대안으로 평가되는 철근 겹침이음 방안을 대상으로 하여 철근겹침이음길이와 이음 부의 영향 등을 실험적으로 검토하고 다음과 같은 결론을 도출하였다.

증기양생에 의한 UHPC 이음부에서 연속된 철근을 사용 한 경우와 동일한 수준의 연속성을 확보하기 위한 철근겹 침이음길이의 최소값은 $150 \mathrm{~mm}$ 로 판단된다.

현장이음부의 설치는 UHPC의 인장기여도를 감소시키 므로 이음부를 설치하지 않은 경우에 비해 약 $70 \%$ 수준의 최대하중을 나타내었다. 이는 경계면이 매끄러운 경우에 대한 결과이므로 표면처리 등을 통해 UHPC의 부착성능을 보다 효율적으로 활용할 수 있는 보완이 필요할 것으로 판 단된다.

위의 결론은 UHPC 교량 바닥판의 프리캐스트 공법 적 용을 위해 필연적으로 발생되는 이음부로서 철근겹침이음 방안의 적합성을 판단하기 위한 기초적 정보를 제공하는 데 유용할 것으로 판단되며, 추후 사용성과 피로를 고려한 성능평가가 수행된다면 실용화가 가능할 것으로 기대된다.

\section{후 기}

이 논문은 한국건설기술연구원의 “하이브리드사장교 바 닥판 개발” 과제의 지원으로 작성되었습니다. 이에 감사드 립니다.

\section{참고문헌}

1. Graybeal, B.A., "UHPC in the U.S. Highway Transportation System," 2nd International Symposium on Ultra High Performance Concrete, Kassel, Germany, 2008, pp. 11-17.

2. Resplendino, J., "Ultra-High Performance Concretes - Recent Realizations and Research Programs on UHPFRC Bridges in France," 2nd International Symposium on Ultra High Performance Concrete, Kassel, Germany, 2008, pp. 31-43.

3. Kim, B.S., Kim, S.W., Park, S.Y., and Koh, K.T., "R\&D Activities and Application of High Performance Concrete to Cable Stayed Bridges," 3rd International Symposium on Ultra High Performance Concrete, Kassel, Germany, 2012, \#1283.

4. Perry, V., and Seibert, P., "Field Cast UHPC Connections for Precast Bridge Elements and Systems," 3rd International Symposium on Ultra High Performance Concrete, Kassel, Germany, 2012, \#1225.

5. Martin, S., and Werner, S., "Investigation on Bonding between Timber and Ultra High Performance Concrete," Construction and Building Materials, Vol. 25, Issue 7, 2011, pp. 3078-3088.

6. Raafat, E., and Donna, C., "Behaviour of Hybrid FRP-UHPC 
Beams subjected to Static Flexural Loading," Composites Part B: Engineering, Vol. 43, Issue 2, 2012, pp. 582-593.

7. Graybeal, B.A., and Swenty, M., "UHPFRC for Prefabricated Bridge Component Connections," 3rd International Symposium on Ultra High Performance Concrete, Kassel, Germany, 2012.

8. Yoo, D.M., Hwang, H.H., Kim, S.T., and Park, S.Y., "An Experimental Study on the Shear Connection for UHPC Deck
Bridge," Journal of the Korean Society for Composite Materials, Vol. 24, No. 1, 2011, pp. 29-33.

9. Hwang, H.H., Yeo, I.S., Cho, K.H., and Park, S.Y., "Evaluations of Flexural Strength for UHPC Deck Joints with Lap-Spliced Reinforced Steel Bar," Journal of the Korean Institute for Structural Maintenance Inspection, Vol. 15, No. 6, 2011, pp. 9299. 